\title{
Yetişkin Popülasyonda Ağız Gargaralarının Kullanım Sıklığı ${ }^{*}$ \\ Frequency of Using Mouthwashes in the Adult Population \\ Alperen Murat Yalnız', Hakan Yasin Gönderii
}

'Restoratif Diş Tedavisi Uzmanı, Serbest Diş Hekimi, https://orcid.org/0000-0001-6886-9042 iiDr. Öğr. Üyesi, Necmettin Erbakan Üniversitesi, Diş Hekimliği Fakültesi, Restoratif Diş Tedavisi AD.

https://orcid.org/0000-0003-4209-5346

öz

\begin{abstract}
Amaç: Bu çalışmanın amacı yetişkin populasyonda gargara kullanım sıklığını öğrenmek ve demografik değişkenler ile gargara kullanımı arasındaki ilişkiyi araştırmaktır.

Yöntem: Toplamda 11 soruluk anket çalışmasının ilk altı sorusunda demografik bilgiler sorulmuştur. Yedinci soruda ağız gargarası kullanımı sorulmuş ve "Hayır" yanıtını verenlerin anketi sona erdirilmiştir. "Evet" yanıtını verenlere ek olarak ağı gargarası kullanmaya nasıı başladığı, hangi amaçla kullandığı, ne sıklıkla kullandığı ve nereden temin ettiği sorulmuş ve verilen yanıtlar kaydedilmiştir. Elde edilen veriler analiz edilmiş ve tanımlayıcı istatistiklerin dışında değişkenler arasındaki ilişkiyi değerlendirmek için Ki-kare testi kullanılmıştır.

Bulgular: Çalışmaya 650 yetişkin birey katııım sağlamıştır. Cinsiyet, yaş, eğitim düzeyi ve sigara kullanımı ile ağız gargarası kullanımı arasında anlamlı bir farklılık bulunamamıştır. "Altı ayda bir defa veya daha sık" ve "Senede bir defa" diş hekimine gidenlerin ağız gargarası kullanımı "Nadiren ya da mecbur kaldıkça" diş hekimine gidenlere göre istatistiksel olarak anlamlı bulunmuştur $(p<0,05)$. “Günde iki defa veya daha fazla” diş fırçalayan bireylerin ağız gargarası kullanım oranı "Günde bir defa” ve "Haftada iki-üç defa” diş fırçalayan bireylere göre anlamlı şekilde yüksek bulunmuştur $(p<0,05)$.

Sonuç: Diş hekimine gitme sıklığı ve diş fırçalama sıklığı gibi faktörlerin ağız gargarası kullanımı ile ilişkili olduğu gösterilmiş olsa da, diğer faktörlerin rolleri tam olarak ifade edilememiştir. Bunların belirlenmesi için gelecekte daha fazla ve daha kapsamlı araştırmalar yapılmalıdır. Ağız ve diş sağlığının korunması ve geliştirilmesi konusunda, ağız gargaralarının önemi ve etkinliği geri planda kalmış ve toplum bilincinin yetersiz olduğu görülmüştür. Toplumdaki bireyler ağız gargaraları konusunda bilgilendirilmeli ve ağız gargarası kullanımı yaygınlaştırılmalıdır.
\end{abstract}

Anahtar Kelimeler: Ağız gargarası, Ağız sağlı̆̆ı, Koruyucu diş hekimliğ

\section{ABSTRACT}

Objective: The aim of this study was to learn the frequency of mouthwash use in the adult population and to investigate the demographic variables with mouthwash use in adult population.

Materials and Methods: Demographic information was asked in the first six questions of the 11-question survey study in total. In the seventh question, the use of mouthwash was asked and the questionnaire of those who answered "No" was ended. Those who answered "Yes" were additionally asked about how they started using mouthwash, for what purpose, how often they used them and where they obtained them, and their answers were recorded. The datas obtained were analyzed and statistics tests done.

Results: 650 adults participated in the study. No significant difference was found between the use of mouthwash and gender, age, education level and smoking. Furthermore significant difference was found between the use of mouthwash and frequency of visiting dentist and brush teeth $(\mathrm{p}<0.05)$.

Conclusion: Although some factors such as the frequency of visiting dentist and brushing teeth have been shown to be associated with mouthwash use, the roles of other factors have not been fully expressed. More and more comprehensive research should be conducted in the future to determine these. It has been observed that the importance and effectiveness of mouthwashes have remained in the background in the protection and improvement of oral and dental health and the public awareness is insufficient. Individuals in the community should be informed about mouthwash and the use of mouthwash should be made widespread.

Key words: Mouthwash, Oral health, Preventive dentistry

\footnotetext{
${ }^{*}$ Mersin Üniversitesi Tıp Fakültesi Lokman Hekim Tıp Tarihi ve Folklorik Tıp Dergisi, 2021; 11 (3): 546-553 DOI:10.31020/mutftd.938644

e-ISSN: 1309-8004, ISSN 1309-761X
}

Geliş Tarihi - Received: 17 Mayıs 2021; Kabul Tarihi - Accepted: 27 Temmuz 2021

Iletişim - Correspondence Author: Alperen Murat Yalnız <alp.yalniz@gmail.com>

Etik Kurul Onayı: Necmettin Erbakan Üniversitesi Diş Hekimliği Fakültesi Etik Kurulu (25.03.2021 tarih ve 2021/03-29 sayı) 


\section{Giriş}

Ağız sağ|ığı, genel vücut sağlığının ayrılmaz bir parçasıdır ve bireylerin sadece sağlam dişlere sahip olmasından daha fazlasını ifade eder. ${ }^{1} 2017$ yılında yayınlanan bir çalışmada, dünya çapında 3.5 milyara yakın insanın ağız hastalıklarından etkilendiği ve en yaygın problemin diş çürükleri olduğu belirtilmiştir. Dünya genelinde 2.3 milyar insanın dişlerinde çürük olduğu ve 530 milyondan fazla çocuğun süt dişlerinde çürük bulunduğu tahmin edilmektedir. ${ }^{2}$ Oldukça yaygın olarak gözlenen ağız hastalıkları, bireylerin faaliyetlerini kısıtlamakta ve yaşam kalitesini önemli ölçüde azaltmaktadır. ${ }^{1}$

Plak, çürükten diş eti hastalığına kadar değişen diş hastalıklarından sorumlu birincil faktördür. Yetersiz ağız hijyeni, plak büyümesinin etiyolojisinde önemli bir role sahiptir. ${ }^{3}$ Düzenli diş fırçalama, plağı ağız içerisinden uzaklaştırmanın temel mekanik yöntemidir ve bu sebeple diş hastalıklarının gelişme riskini azaltır. ${ }^{4}$ Ancak diş fırçası dişler arasındaki kontak noktasının altındaki diş yüzeylerine erişemez. Dişler arasında biriken maddeleri daha etkili bir şekilde çıkarmak ve diş fırçalamayı desteklemek için arayüz fırçası veya diş ipi önerilir. ${ }^{5}$ Yapılan çalışmalar bu temizleme araçlarının plak ve dişeti hastalığını kontrol etmek için yeterli olmadığını göstermiştir. ${ }^{6}$ Bu nedenle dişleri fırçalamayı desteklemek için, ağız gargaraları gibi yardımcı materyallerin kullanımı önerilir. Ancak bu yardımcı materyaller temel mekanik temizleme yöntemlerine ek olarak kullanılmalı ve ikamesi olarak görülmemelidir. ${ }^{7}$

Koruyucu diş hekimliği kavramının gelişmesi ve toplumdaki bilinç seviyesinin artması ile bireylerin ağız bakım alışkanlıkları gelişmiştir. İlk olarak ağız kokusunun giderilmesi gibi amaçlarla kullanılan ağız gargaraları, günümüzde birçok faydasından dolayı ağız hijyeni alışkanlıklarının önemli bir parçası haline gelmektedir. ${ }^{8} \mathrm{Ağız}$ gargaraları, oral hijyen kullanımına ek olarak plak ve çürük oluşumunu engellemeye destek olması ve periodontal problemlerin önlenmesi ve tedavisi gibi birçok durumda kullanılmaktadır. ${ }^{9}$ Ağız gargaraları güzel kokulu, ferahlatıcı etkisi olan steril olmayan solüsyonlar olarak tanımlanabilir. Ağız gargaraları; kozmetik, tedavi edici ya da her ikisinin kombinasyonu şeklindedir. Kozmetik amaçla kullanılan ağız gargaraları antimikrobiyal değildir, ancak ağızda hoş bir tat bırakırlar ve diş fırçalama sonrası ağız içerisindeki birikintileri ortadan kaldırarak ağız kokusunu azaltırlar. Tedavi edici gargaralar ise kozmetik ürünlerin yararlarının yanısıra florid veya klorheksidin gibi aktif maddelerle ağız sağlığına yardımcı olur. ${ }^{10}$ Klorheksidin'in dental plağı azaltma özelliği bilinmektedir. Çinko içeren ağız gargaraları tek başına veya düşük konsantrasyonlarda klorheksidin ile kombinasyon halinde ağız kokusuna karşı etkilidir. Ağız gargarası kullanımına bağlı olarak ortaya çıkan yan etkiler nadir olsa da, ağız gargaralarının içeriklerindeki bileşenlere karşı gelişen alerjik reaksiyonlar bildirilmiştir. ${ }^{11}$

$\mathrm{Bu}$ çalışmanın amacı yetişkin populasyonda gargara kullanım sıklığını değerlendirmek ve demografik değişkenler ile gargara kullanımı arasındaki ilişkiyi araştırmaktır.

\section{Gereç ve Yöntem}

Herhangi bir saha çalışmasına başlamadan önce ilgili araştırma için Necmettin Erbakan Üniversitesi Diş Hekimliği Fakültesi Etik Kurulu'ndan 25.03.2021 tarih ve 2021/03-29 sayı ile etik kurul onayı alınmıştır. Araştırmamız, toplam on bir sorudan oluşan ve internet üzerinden doldurulan bir anket çalışmasıdır. Anket soruları, daha önce yayınlanmış çalışmalardan geliştirilip oluşturulmuştur. ${ }^{3,10}$ Hazırlanan anket formu katılımcılara sosyal paylaşım siteleri ve e-posta yoluyla iletilmiştir. Araştırmamızın anket formu; 26.03.202119.04.2021 tarihleri arasında katılımcılar tarafından internet üzerinden doldurulmuştur. Tüm katılımcılar, ankete başlamadan önce bilgilendirilmiş gönüllü olur formunu okuyup doldurmuştur. Anketin ilk altı sorusunda cinsiyet, yaş, eğitim düzeyi, diş hekimine gitme ve diş fırçalama sıklığı, sigara kullanımı sorulmuştur. Yedinci soruda ağız gargarası kullanımı sorulmuş ve "Hayır" yanıtını verenlerin anketi sona erdirilmiştir. "Evet" yanıtını verenlere ek olarak ağız gargarası kullanmaya nasıl başladığı, hangi amaçla 
kullandığı, ne sıklıkla kullandığı ve nereden temin ettiği sorulmuş ve verilen yanıtlar kaydedilmiştir. Çalışmaya internet erişimi ve kullanımı olan on sekiz yaş üzeri yetişkin bireyler dahil edilmiştir. İnternet erişimi veya kullanımı olmayan yetişkin bireyler ve on sekiz yaş altı bireyler çalışmaya dahil edilmemiştir. Elde edilen veriler istatistiksel olarak analiz edilmiştir. Tanımlayıcı istatistiklerin dışında değişkenler arasındaki ilişkiyi değerlendirmek için Ki-kare testi kullanılmıştır. İstatistiksel açıdan anlamlılık düzeyi $p<0,05$ olarak kabul edilmiştir.

\section{Bulgular}

Toplamda 650 kişi anketimize katıım sağlamıştır. Yetişkin bireyler arasında yapılan bu çalışmaya katılanların cinsiyet ve yaşa göre dağılımı Tablo 1'de gösterilmiştir. Katılımcıların yarısından fazlası (330 kişi, \%50.8) 2640 yaş aralı̆̆ındadır (Şekil 1). Anket çalışmasının asıl amacı olan ağız gargarası kullanımı sorusuna "Evet" cevabı verenlerin sayısı 200 kişi (\%30.8), "Hayır" cevabı verenlerin sayısı 450 kişidir (\%69.2) (Tablo 2).

Tablo 1. Katılımcıların yaş ve cinsiyet dağılımı

\begin{tabular}{lcc}
\hline & \multicolumn{2}{c}{ Cinsiyet } \\
Yaş Grupları & Erkek n(\%) & Kadın n(\%) \\
\hline $\mathbf{1 8 - 2 5}$ & $29(\% 4.5)$ & $100(\% 15.4)$ \\
$\mathbf{2 6 - 4 0}$ & $187(\% 28.8)$ & $143(\% 22)$ \\
$\mathbf{4 0}$ yaş üstü & $125(\% 19.2)$ & $66(\% 10.1)$ \\
Toplam & $341(\% 52.5)$ & $309(\% 47.5)$ \\
\hline
\end{tabular}

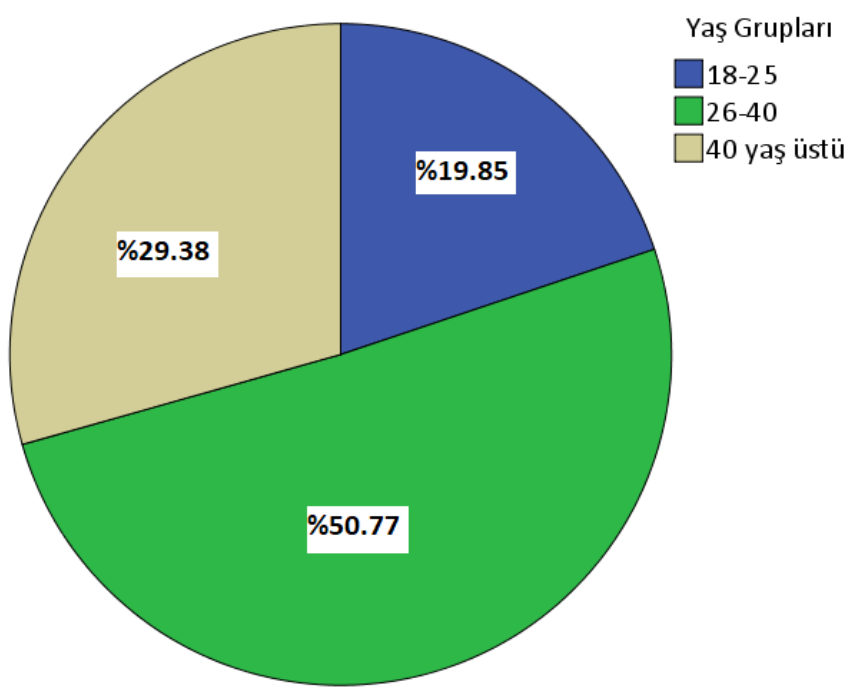

Şekil 1. Katılımcı yaş gruplarının yüzdelik dağılımı

Tablo 2'de gösterildiği gibi çalışmamıza katılan kadınların ağız gargarası kullanım oranı erkeklere göre daha fazladır (sırasıyla \%35.6 ve \%26.4 ), ancak istatistiksel olarak anlamlı bir farklılık bulunamamıştır $(p>0,05)$.

Tablo 2. Cinsiyete göre ağız gargarası kullanım dağıımı

\begin{tabular}{llll}
\hline \multicolumn{4}{c}{ Ağız gargarası kullanımı } \\
Cinsiyet & Evet $\mathbf{n ( \% )}$ & Hayır $\mathbf{n ( \% )}$ & Toplam $\mathbf{n ( \% )}$ \\
\hline Erkek & $90(26.4)$ & $251(73.6)$ & $341(100)$ \\
Kadın & $110(35.6)$ & $199(64.4)$ & $309(100)$ \\
Toplam & $200(30.8)$ & $450(69.2)$ & $650(100)$ \\
\hline
\end{tabular}

Ağız gargarası kullanımının yaş grupları ile ilişkisi incelendiğinde, istatistiksel olarak farklıık olmamasına rağmen $(p>0,05)$, oransal olarak bireylerin yaşları ilerledikçe gargara kullanımının azaldığı Tablo $\mathbf{3}^{\prime}$ te gösterilmiştir. Ankete katılanlara eğitim düzeyleri sorulduğunda; 10 kişi (\%1.5) "ilkokul", 10 kişi (\%1.5) 
"Ortaokul", 28 kişi (\%4.3) "Lise", 244 kişi (\%37.5) "Ön lisans/lisans" ve 358 kişi (\%55.1) "Yüksek lisans/doktora" olarak cevaplamıştır. Eğitim düzeylerine göre ağız gargarası kullanım dağılımı Tablo 4'te gösterilmiştir.

Tablo 3. Yaş gruplarına göre ağız gargarası kullanım dağılımı

\begin{tabular}{llll}
\hline & \multicolumn{2}{c}{ Ağız gargarası kullanımı } & \\
Yaş Grupları & Evet $\mathbf{n ( \% )}$ & Hayır $\mathbf{n ( \% )}$ & Toplam $\mathbf{n}(\%)$ \\
\hline $\mathbf{1 8 - 2 5}$ & $49(38)$ & $80(62)$ & $129(100)$ \\
$\mathbf{2 6 - 4 0}$ & $104(31.5)$ & $226(68.5)$ & $330(100)$ \\
$\mathbf{4 0}$ yaş üstü & $47(24.6)$ & $144(75.4)$ & $191(100)$ \\
Toplam & $200(30.8)$ & $450(69.2)$ & $650(100)$ \\
\hline
\end{tabular}

Tablo 4. Eğitim düzeylerine göre ağız gargarası kullanım dağılımı

\begin{tabular}{llll}
\hline & \multicolumn{2}{c}{ Ağız gargarası kullanımı } & \\
Eğitim Düzeyi & Evet $\mathbf{n ( \% )}$ & Hayır $\mathbf{n ( \% )}$ & Toplam $\mathbf{n}(\%)$ \\
\hline İlkokul & $0(0)$ & $10(100)$ & $10(100)$ \\
Ortaokul & $1(10)$ & $9(90)$ & $10(100)$ \\
Lise & $7(25)$ & $21(75)$ & $28(100)$ \\
Ön Lisans/Lisans & $68(27.9)$ & $176(72.1)$ & $244(100)$ \\
Yüksek Lisans /Doktora & $124(34.6)$ & $234(65.4)$ & $358(100)$ \\
Toplam & $200(30.8)$ & $450(69.2)$ & $650(100)$ \\
\hline
\end{tabular}

Diş hekimine gitme sıklıkları sorulduğunda, büyük çoğunluk (439 kişi, \%67.5) "Nadiren/mecbur kaldıkça" gittiklerini belirtmiştir. Tablo 5'te gösterildiği gibi; 131 kişi (\%20.1) "Senede bir defa", 80 kişi de (\%12.3) "Altı ayda bir veya daha sık" olarak diş hekimlerine gittiklerini belirtmiştir. "Altı ayda bir defa veya daha sık" ve "Senede bir defa" diş hekimine gidenlerin ağız gargarası kullanımı "Nadiren ya da mecbur kaldıkça" diş hekimine gidenlere göre istatistiksel olarak daha yüksek bulunmuştur $(p<0,05)$.

Tablo 5. Diş hekimine gitme sıklığına göre ağız gargarası kullanım dağılımı

\begin{tabular}{|c|c|c|c|c|}
\hline \multirow[b]{2}{*}{ Ağız gargarası kullanımı } & \multicolumn{3}{|c|}{ Diş hekimine gitme sıklığı } & \multirow[b]{2}{*}{$\begin{array}{l}\text { Toplam } \\
\mathrm{n}(\%)\end{array}$} \\
\hline & $\begin{array}{l}\text { Altı ayda bir defa } \\
\text { veya daha sık } n(\%)\end{array}$ & $\begin{array}{l}\text { Senede bir defa } \\
n(\%)\end{array}$ & $\begin{array}{l}\text { Nadiren/ Mecbur } \\
\text { kaldıkça } n(\%)\end{array}$ & \\
\hline Evet & $36^{a}(45)$ & $55^{a}(42)$ & $109^{\mathrm{b}}(24.8)$ & $200(30.8)$ \\
\hline Hayır & $44^{a}(55)$ & $76^{a}(58)$ & $330^{b}(75.2)$ & $450(69.2)$ \\
\hline Toplam & 80 (100) & $131(100)$ & 439 (100) & 650 (100) \\
\hline
\end{tabular}

a,b: Farklı küçük harflerle gösterilen gruplar arasında istatistiksel olarak anlamlı farklılık vardır $\left({ }^{*} p<0,05\right)$.

Diş fırçalama sıklıkları sorulduğunda ise, 284 kişinin (\%43.7) "Günde iki defa veya daha fazla", 269 kişinin (\%41.4) "Günde bir defa", 65 kişinin (\%10) "Haftada iki-üç defa”, 16 kişinin (\%2.5) "Haftada bir defa", 16 kişinin de (\%2.5) "Nadiren" dişlerini fırçaladığını belirtmiştir. Diş fırçalama sıklığına göre ağız gargarası kullanımı incelendiğinde, Tablo 6' da gösterildiği gibi "Günde iki defa veya daha fazla" diş fırçalayan bireylerin ağız gargarası kullanım oranı "Günde bir defa" ve "Haftada iki-üç defa" diş fırçalayan bireylere göre anlamlı şekilde yüksek bulunmuştur $(p<0,05)$.

Tablo 6. Diş fırçalama sıklığına göre ağız gargarası kullanım dağılımı

\begin{tabular}{|c|c|c|c|c|c|c|}
\hline \multicolumn{7}{|c|}{ Diş fırçalama sıklığı } \\
\hline $\begin{array}{l}\text { Ağız gargarası } \\
\text { kullanımı }\end{array}$ & $\begin{array}{l}\text { defa veya } \\
\text { daha fazla } \\
\mathrm{n}(\%)\end{array}$ & $\begin{array}{l}\text { Günde bir } \\
\text { defa } \\
n(\%)\end{array}$ & $\begin{array}{l}\text { Haftada iki-üç } \\
\text { defa } \\
n(\%)\end{array}$ & $\begin{array}{l}\text { Haftada bir defa } \\
\mathrm{n}(\%)\end{array}$ & $\begin{array}{l}\text { Nadiren } \\
\mathrm{n}(\%)\end{array}$ & $\begin{array}{l}\text { Toplam } \\
\mathrm{n}(\%)\end{array}$ \\
\hline Evet & $112^{\mathrm{a}}(39.4)$ & $65^{b}(24.2)$ & $17^{b}(26.2)$ & $3^{a, b}(18.8)$ & $3^{\mathrm{a}, \mathrm{b}}(18.8)$ & $200(30.8)$ \\
\hline Hayır & $172^{\mathrm{a}}(60.6)$ & $204^{b}(75.8)$ & $48^{b}(73.8)$ & $13^{\mathrm{a}, \mathrm{b}}(81.3)$ & $13^{a, b}(81.3)$ & $450(69.2)$ \\
\hline Toplam & $284(100)$ & $269(100)$ & $65(100)$ & $16(100)$ & $16(100)$ & $650(100)$ \\
\hline
\end{tabular}

a,b: Farklı küçük harflerle gösterilen gruplar arasında istatistiksel olarak anlamlı farklılık vardır $(* p<0,05)$. 
Ankete katılanlara sigara kullanıp kullanmadıkları sorulduğunda; Tablo 7'de gösterildiği gibi 169 kişi (\%26) "Evet", 481 kişi (\%74) "Hayır" cevabını vermiştir. Sigara kullanımının ağız gargarası kullanımı ile ilişkisi incelendiğinde istatistiksel olarak anlamlı bir farklılık bulunamamıştır $(p>0,05)$.

Tablo 7. Sigara kullanımına göre ağız gargarası kullanım dağılımı

\begin{tabular}{llll}
\hline & \multicolumn{2}{c}{ Ağız gargarası kullanımı } & \\
Sigara kullanımı & Evet $\mathbf{n ( \% )}$ & Hayır $\mathbf{n ( \% )}$ & Toplam $\mathbf{n ( \% )}$ \\
\hline Evet & $57(33.7)$ & $112(66.3)$ & $169(100)$ \\
Hayır & $143(29.7)$ & $338(70.3)$ & $481(100)$ \\
Toplam & $200(30.8)$ & $450(69.2)$ & $650(100)$ \\
\hline
\end{tabular}

Ağız gargarası kullanan 200 kişiye ağız gargaralarını kullanmaya nasıl başladıkları sorulduğunda, 67 kişi (\%33.5) "Diş hekimi tavsiyesi", 65 kişi (\%32.5) "Aile/yakın çevre tavsiyesi", 49 kişi (\%24.5) "Televizyon reklamları", 19 kişi de (\%9.5) "internet reklamları" ile başladıklarını işaretlemiştir (Şekil 2). Ağız gargarası kullanan 124 kişi (\%62) "Ağız hijyeni sağlamak" için, 19 kişi (\%9.5) "Diş eti problemlerini azaltmak" için, 22 kişi (\%11) "Sigara ve ağız kokusunun giderilmesi" için, 23 kişi (\%11.5) "Çürük ve ağız hastalıklarını önlemek" için, 12 kişi (\%6) "Aft vb. ağız lezyonları" için kullandıklarını belirtmiştir (Şekil 3). Ağız gargaralarını hangi sıklıkla kullandıkları sorulduğunda, 18 kişi (\%9) "Günde iki defa veya daha fazla", 66 kişi (\%33) "Günde bir defa", 60 kişi (\%30) "Haftada iki-üç defa", 25 kişi (\%12.5) "Haftada bir defa", 31 kişi (\%15.5) ise "Nadiren" kullandıklarını işaretlemiştir (Şekil 4). Son olarak ağız gargaralarını nereden aldıkları sorulduğunda büyük bir çoğunluk (140 kişi, \%70) "Market" şıkkını seçmiştir (şekil 5). Eczaneden satın alanların sayısı 49 kişi (\%24.5), internet üzerinden satın alanların sayısı ise sadece 11 kişidir (\%5.5).

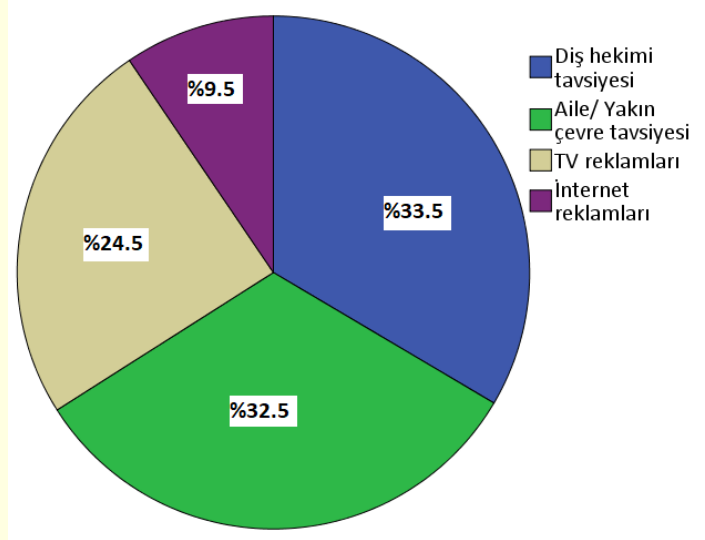

Şekil 2. Katılımcıların ağız gargarası kullanmaya nasıl başladıklarının dağılımı

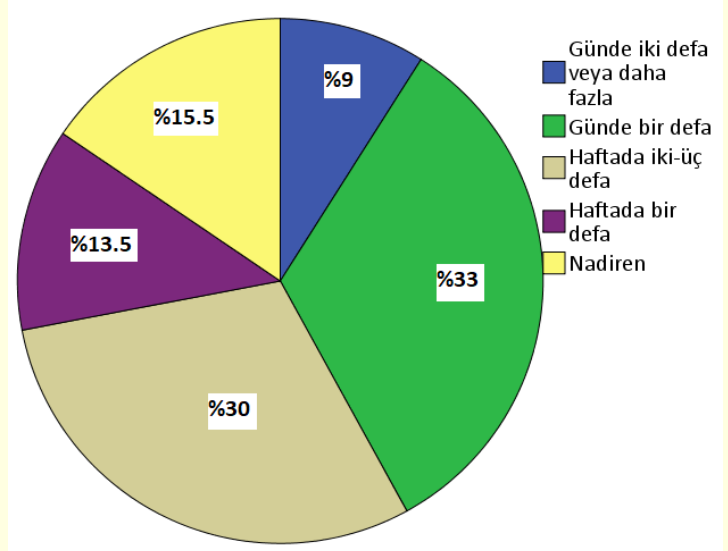

Şekil 4. Ağız gargaralarının kullanım sıklığı

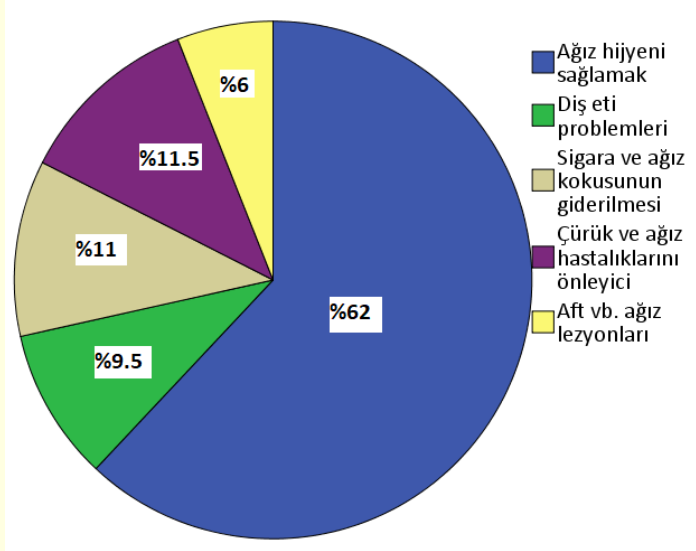

Şekil 3. Ağız gargaralarının kullanım amacına göre dağıııı

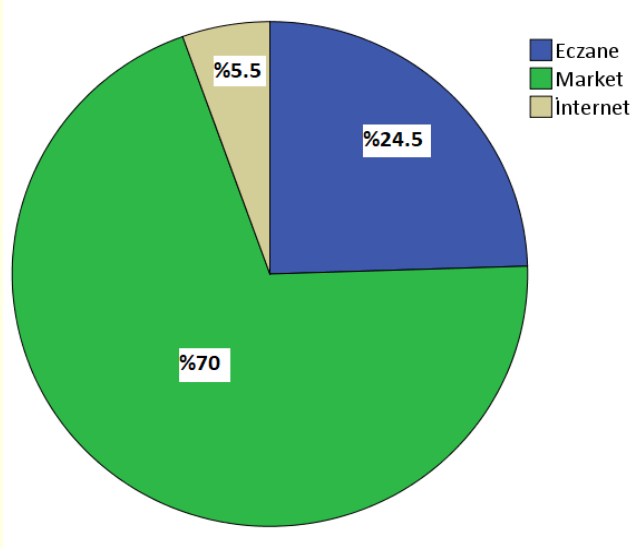

Şekil 5. Ağız gargaralarının satın alındıkları yerlerin dağıımı 


\section{Tartışma}

Oral hijyen, genel toplum sağlığını etkileyen önemli bir faktördür. Oral hijyen alışkanlıkları gibi sağlıkla ilgili davranışların zamanla değiştirilmesi genellikle zordur. Koruyucu diş hekimliği çalışmaları ile bireylerin ağız bakım alışkanlıklarında gelişmeler ve değişiklikler olmuştur. Diş fırçalamaya ek olarak, diş ipi, ara yüz fırçaları ve ağız gargaralarının kullanımı yaygınlaşmaya başlamıştır. ${ }^{4}$ Yaptığımız araştırmanın amacı, yetişkin bireyler arasındaki ağız gargarası kullanım sıklığını araştırmaktır. Ayrıca; gargara kullanımının cinsiyet, yaş, eğitim düzeyi, diş hekimine gitme sıklığı, diş fırçalama sıklığı ve sigara kullanımı ile ilişkisini sorgulamaktır.

İskoçya, İsveç ve Malezya'da yapılan birçok araştırmada kadınların ağız gargarasını daha fazla kullandığı belirtilmiştir. ${ }^{3,11,12}$ Çalışmamızda ise cinsiyet ile ağız gargarası kullanımı arasında istatistiksel olarak anlamlı bir sonuç elde edilmese de, kadınların ağız gargarası kullanım oranının erkeklere göre daha fazla olduğu görülmüştür. Bu farklılığın sebebi; kadınların kişisel ve ağız hijyenleri ile daha fazla ilgilenmeleri ve ağız gargaralarının kozmetik ürünlerle yakın ilişkisi olabilir. ${ }^{3,11}$ Ağız gargarası kullanımının yaş ile ilişkisi incelendiğinde ise katılımcıların yaşları arttıkça ağız gargarası kullanım oranının azaldığı görülmüştür. Ancak bu azalma istatistiksel olarak anlamlı bulunmamıştır. Bu azalmanın sebebi; bireylerin yaşları ilerledikçe ağızlarında bulunan doğal diş sayılarındaki azalma ve protez diş kullanmaları ile ilişkili olabilir. ${ }^{3}$ Ağız gargarası kullanımında cinsiyet ve yaş faktörlerinin belirleyici olduğunu söyleyebilmek için daha geniş kapsamlı çalışmalara ihtiyaç vardır.

Macfarlane ve ark. 2011 yılında yaptıkları bir çalışmada gargara kullanımı ile eğitim düzeyi arasında istatistiksel olarak anlamlı bir ilişki bulunmuş ve yüksek lisans eğitim düzeyindeki kişilerin anlamlı seviyede daha fazla ağız gargarası kullandığı belirtilmiştir. ${ }^{3}$ Çalışmamıza katılan bireylerin büyük kısmı "Ön lisans/lisans" ve "Yüksek lisans/doktora" eğitim düzeyindedir. Ağız gargarası kullanımı oransal olarak "Ön lisans/lisans" eğitim düzeyinde \%27.9, "Yüksek lisans/doktora" eğitim düzeyinde ise \%34.6 bulunmuştur. Ancak, çalışmamıza "ilkokul”, "Ortaokul” ve "Lise" eğitim düzeylerinde yeterli katılım olmadığı için eğitim düzeyi ile ağız gargarası kullanımı arasındaki ilişkiye ait kesin bir sonuç tespit edilememiştir.

Kişilerin herhangi bir problemi olmasa da altı ayda bir ya da en geç senede bir defa olmak üzere diş hekimine rutin kontroller için gitmeleri önerilir. Bu kontrollerde diş hekimleri; dişler, dişetleri ve ağız içini kapsamlı bir muayeneden geçirerek, hastalık veya diğer problemlerin belirtilerini ararlar. Amaç, mümkün olan en erken sürede tanı koymak ve tedavi ederek ağı sağlığını korumak, problemleri ciddileşmeden önlemektir. Çalışmamıza katılan kişilerin çoğunluğu "Nadiren ya da mecbur kaldıkça" diş hekimine gittiklerini belirtmiştir. "Altı ayda bir defa veya daha sık" ve "Senede bir defa" diş hekimine giden bireylerin ağız gargarası kullanımı "Nadiren ya da mecbur kaldıkça" diş hekimine giden bireylere oranla anlamlı şekilde daha yüksek bulunmuştur. Bu sonuç, diş hekimine düzenli olarak giden kişilerin ağız ve diş sağlığına daha fazla önem verdiğini ve ağız gargaralarını daha fazla kullandığını göstermektedir. Diş hekimleri de hastalarına ağız gargarası ve diğer oral hijyen araçlarını anlatmalı ve kullanımını yaygınlaştırmalıdır.

Yapılan bir araştırmada, hem diş fırçalama hem de diş ipi kullanma sıklığının ağız gargarası kullanım sıklığı ile pozitif yönde ilişkili olduğu görülmüştür. ${ }^{3}$ Çalışmamızda diş fırçalama sıklı̆ına göre ağız gargarası kullanımı incelendiğinde, "Günde iki defa veya daha fazla" diş fırçalayan bireylerin ağız gargarası kullanım oranı "Günde bir defa" ve "Haftada iki-üç defa" diş fırçalayan bireylere göre anlamlı şekilde yüksek bulunmuştur $(p<0,05)$. Ağız hijyeni ve sağlığına dikkat eden kişilerin, diş plağını mekanik olarak uzaklaştırırken ek olarak ağız gargarası kullandıklarını belirtmişlerdir. ${ }^{3}$ Dumitrescu ve arkadaşları yaptıkları çalışmada, kişilerin kendini beğenme dereceleri, kişisel bakımları ve diş hekimi ziyaretleri ile diş ipi ve gargara kullanımı arasında bir ilişki olduğunu öne sürmektedir. ${ }^{13}$ 
Ağız gargaraların etkinliği, içeriğinde bulunan aktif bileşenin konsantrasyonu ve işlevi ile ilgilidir. Klorheksidin etkili bir antimikrobiyal ajandır. Klorheksidin içeren topikal ağız gargaralarının dental plak ve gingivitise karşı etkinliği yapılan çalışmalarda gösterilmiştir. ${ }^{14}$ Ancak klorheksidin içeren ağız gargaralarının, ağız içi yüzeylerin ve dişlerin renklenmesine, tat alma bozukluğuna ve alerjik reaksiyonlara sebep olabileceği hatta anaflaktik reaksiyona bile yol açabileceği unutulmamalıdır. ${ }^{15,16}$

Etanol; geniş antimikrobiyal aktiviteye sahip bir alkol türüdür ve birçok ağız gargarası içerisinde çözücü ve koruyucu olarak işlev görür. ${ }^{9}$ McCullough ve Farah, 2008 yılında yaptıkları bir çalışmada içeriklerinde alkol bulunan gargaraların kullanımının ağız kanseri riskini artırabileceği öne sürmüştür. ${ }^{17}$ La Vecchia 2009 yılında yayınlandığı bir derlemede, bu bağlantının epidemiyolojik kanıtlarla desteklenmediğini göstermiştir. ${ }^{18}$ Ancak Wirth ve arkadaşlarının 2012 yılında yaptığı çalışma gargarayı kanserle ilişkilendiren çelişkili sonuçlara sahiptir. ${ }^{19}$ Bu nedenle, ağız gargaralarındaki alkolün etkilerini araştırmak için daha çok çalışmaya intiyaç vardır.

Ağız gargaralarının hangi amaçla kullanıldıkları sorulduğunda, gargara kullanan katılımcıların büyük bir kısmı (\%62) "Ağız hijyeni sağlamak" için kullandıklarını belirtmiştir. Ağız gargaraları, ağız kokusunu gidermek için kullanılan yaygın yöntemlerden biridir. ${ }^{20}$ Sigara kullanan kişiler, genellikle ağız kokusunu gidermek veya sigaranın ağızda kalan tadını azaltmak için ağız gargaralarını kullanmaktadır. Çalışmamıza katılan kişilerin \%11'i de "Ağız ve sigara kokusunun giderilmesi" için ağız gargaralarını kullandıklarını belirtmiştir. Ayrıca, ağız içi cerrahi işlemler sonrası, diş eti problemlerini azaltmak, aft vb. ağız lezyonlarının tedavisi, çürük önleyici etkisi için de ağız gargaraları kullanılmaktadır. Yayınlanan bir derlemede sabit ortodontik apareylere sahip hastalarda karyojenik plağı azaltmak ve kontrol etmek için ağız gargarası kullanımının etkinliği vurgulanmıştır. ${ }^{21}$

\section{Kısıtlılıklar}

Fikir aşamasında yüz yüze yapılması planlanan çalışma pandemi koşulları sebebiyle katılımcıların anketi internet üzerinden doldurmalarıyla yapılmıştır. Çalışmaya katılan bireylerin internet üzerinden anket formunu doldururken gerçeği yansıtmayan cevaplar vermiş olma olasılığı, bu çalışmanın kısıtılıklarından birisidir. Çalışmaya katılan bireylerden eğitim düzeyi düşük olanların sayısının çok az olması da çalışmayı kısıtlayıcı yönlerden biridir. Eğitim düzeyi düşük bireylerin internet ve de özellikle sosyal paylaşım sitelerini kullanmamalarından dolayı çalışmanın kendilerine ulaşamamış olma ihtimali bulunmaktadır. İleride yapılacak çalışmalarda daha doğru sonuçlar elde etmek için bu noktalara dikkat edilerek verilerin toplanması önerilmektedir.

\section{Sonuç}

Bu çalışmada cinsiyet, yaş, eğitim düzeyi, diş hekimine gitme ve diş fırçalama sıklı̆̆ı, sigara kullanımı gibi çeşitli faktörlerin ağız gargarası kullanımıyla ilişkisi araştırımıştır. Diş hekimine gitme sıklığı ve diş fırçalama sıklığı gibi bazı faktörlerin ağız gargarası kullanımı ile ilişkili olduğu gösterilmiş olsa da, diğer faktörler ile ağız gargarası kullanımı arasında herhangi bir ilişki saptanamamıştır. Bunların belirlenmesi için gelecekte daha fazla ve daha kapsamlı araştırmalar yapılmalıdır. Ağız ve diş sağlığının korunması ve geliştirilmesi konusunda, ağız gargaralarının önemi ve etkinliği geri planda kalmış ve toplum bilincinin yetersiz olduğu görülmüştür. Toplumdaki bireyler ağız gargaraları konusunda bilgilendirilmeli ve ağız gargarası kullanımı yaygınlaştırılmalıdır.

\section{Bilgi}

Çıkar çatışması bulunmamaktadır. Bu çalışmada herhangi bir fon veya destekten yararlanılmamıştır. 


\section{Etik Onay}

Herhangi bir saha çalışmasına başlamadan önce ilgili araştırma için Necmettin Erbakan Üniversitesi Diş Hekimliği Fakültesi Etik Kurulu'ndan 25.03.2021 tarih ve 2021/03-29 sayı ile etik kurul onayı alınmıştır.

\section{Araştırmacı Katkı Oranı Beyanı}

Alperen Murat Yalnız: Fikir, tasarım, danışmanlık/denetleme, analiz ve yorum, kaynak taraması, makale yazımı, eleştirel inceleme.

Hakan Yasin Gönder: Fikir, tasarım, danışmanlık/denetleme, analiz ve yorum, kaynak taraması, makale yazımı, eleştirel inceleme.

\section{Kaynaklar}

1. Petersen PE. The World Oral Health Report 2003: continuous improvement of oral health in the 21st century--the approach of the WHO Global Oral Health Programme. Community Dent Oral Epidemiol 2003;31 Suppl 1:3-23.

2. GBD 2017 Disease and Injury Incidence and Prevalence Collaborators. Global, regional, and national incidence, prevalence, and years lived with disability for 354 diseases and injuries for 195 countries and territories, 1990-2017: a systematic analysis for the Global Burden of Disease Study 2017 [published correction appears in Lancet. 2019 Jun 22;393(10190):e44]. Lancet 2018;392(10159):1789-1858.

3. Macfarlane TV, et al. Mouthwash use in general population: results from adult dental health survey in grampian, Scotland. J Oral Maxillofac Res 2011;1(4):e2.

4. Daly CG. Prescribing good oral hygiene for adults. Aust Prescr 2009;32:72-5.

5. Kiger RD, Nylund K, Feller RP. A comparison of proximal plaque removal using floss and interdental brushes. J Clin Periodontol 1991;18(9):681-684.

6. Asadoorian J. Therapeutic oral rinsing with commercially available products: Position paper and statement from the Canadian Dental Hygienists Association. Can J Dent Hyg 2016;3:126-39

7. Eley BM. Antibacterial agents in the control of supragingival plaque--a review. Br Dent J 1999;186(6):286-296.

8. Holm-Pedersen P. Pathology and treatment of periodontal disease. In: Holm-Pedersen P, Löe H, Editors. Geriatric Dentistry: A Textbook of Oral Gerontology. Copenhagen: Munksgaard; 1986. pp:277-289.

9. Moran JM. Home-use oral hygiene products: mouthrinses. Periodontol 2000 2008;48:42-53.

10. Gömeç Y, Öncü B, Yaman B. Toplumumuzda ağız gargaralarının kullanım sıklığı. Journal of Istanbul University Faculty of Dentistry 2011; 44(2): 115-124.

11. Särner B, et al. Use of different mouthrinses in an adult Swedish population. Swed Dent J 2012;36(1):53-60.

12. Mitha S, et al. Use and Perceived Benefits of Mouthwash among Malaysian Adults: An Exploratory Insight. J Adv Oral Res 2016;7(3):7-14

13. Dumitrescu AL, Toma C, Lascu V. Self-liking, self-competence, body investment and perfectionism: associations with oral health status and oral-health-related behaviours. Oral Health Prev Dent 2009;7(2):191-200.

14. Killoy WJ. The use of local -delivered chlorhexidine in the treatment of periodontitis. Clinical results. J Clin Periodontol 1988;25:953-958.

15. Matthijs S, Adriaens PA. Chlorhexidine varnishes: a review. J Clin Periodontol 2002 Jan;29(1):1-8.

16. Krautheim $A B$, Jermann $T H$, Bircher AJ. Chlorhexidine anaphylaxis: case report and review of the literature. Contact Dermatitis $2004 \mathrm{Mar} ; 50(3): 113-6$.

17. McCullough MJ, Farah CS. The role of alcohol in oral carcinogenesis with particular reference to alcohol-containing mouthwashes. Aust Dent J 2008 Dec;53(4):302-5.

18. La Vecchia C. Mouthwash and oral cancer risk: an update. Oral Oncol 2009 Mar;45(3):198-200.

19. Wirth T, et al. Can Alcohol Intake from Mouthwash be Measured in Epidemiological Studies? Development and Validation of Mouthwash Use Questionnaire with Particular Attention to Measuring Alcohol Intake from Mouthwash. J Oral Maxillofac Res 2012 Oct 1;3(3):e1.

20. Fedorowicz Z, et al. Mouthrinses for the treatment of halitosis. Cochrane Database Syst Rev 2008 Oct 8;(4):CD006701.

21. Pithon MM, et al. Assessment of the effectiveness of mouthwashes in reducing cariogenic biofilm in orthodontic patients: a systematic review. J Dent 2015 Mar;43(3):297-308. 